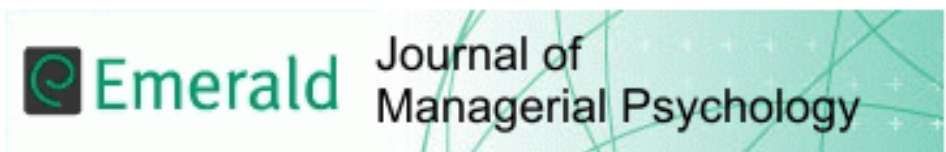

Authentic leadership and employee health: A conditional process model

\begin{tabular}{|r|l|}
\hline Journal: & Journal of Managerial Psychology \\
\hline Manuscript ID & JMP-07-2020-0362.R1 \\
\hline Manuscript Type: & Research Paper \\
\hline Keywords: & $\begin{array}{l}\text { authentic leadership, well-being, Authenticity, Resources, Health and } \\
\text { safety }\end{array}$ \\
\hline \multicolumn{2}{|l}{} \\
\hline
\end{tabular}

SCHOLARONE ${ }^{m}$

Manuscripts 


\title{
Title: Authentic leadership and employee health: A conditional process model
}

\begin{abstract}
Purpose - The purpose of this paper is to examine the effect of authentic leadership on employees' health via employees' perception of climate of authenticity across two studies. In Study 2, we additionally explore the moderating role of employees' neuroticism.
\end{abstract}

Design/methodology/approach - The hypotheses were tested across two studies using twowave survey data. In Study $1(n=104)$, the mediation hypothesis was tested. Study $2(n=$ 146) extended Study 1 and examined the moderated mediation model.

Findings - Across both studies, authentic leadership is positively related to employee health, and employees' perceived climate of authenticity mediates this relationship. Study 2 additionally shows that employees' neuroticism moderates this indirect effect such that perceived climate of authenticity instigated by authentic leadership is particularly conducive for employees high in neuroticism as opposed to those low in neuroticism.

Practical implications - Findings emphasize the health-promoting effect of authentic leadership. It is recommended that organizations cascade, through their leaders, emotional display rules that encourage genuine emotional expression.

Originality/value - This paper addresses gaps in the leadership literature through investigating perceived climate of authenticity, a mediating variable that lies at the heart of authentic leadership, and integrating the role of employees' personality in the leadership process.

Keywords -leadership, authentic leadership, climate of authenticity, health, conservation of resources theory

Paper type - Research paper 


\section{Introduction}

Poor health carries high costs for individuals and organizations. Individuals who are physically and mentally unwell are less likely to live long and fulfilled lives (Foreman et al., 2018), while the financial burden of ill-health due to sickness absence, short-term disability and presenteeism weighs heavily on organizations (Goetzel et al., 2004). Leaders are in a crucial position to positively affect employees' health given that they can be regarded as the 'linking pin' between organizational policies and employees (Hammer \& Zimmerman, 2011).

However, despite its considerable practical significance, leadership research has long not paid sufficient attention to health. Initially, researchers gave precedence to performance, only regarding health and well-being as means to achieving performance (Guest, 2017). When finally studied as primary outcomes, research overwhelmingly focused on transformational leadership (Inceoglu, Thomas, Chu, Plans, \& Gerbasi, 2018; Skakon, Nielsen, Borg, \& Guzman, 2010), a leadership style developed around the premise that it yields performance 'beyond expectations' and not health (Bass, 1985). In light of recent calls for research to focus on exploring specific outcomes that have been theoretically linked to the respective leadership style to advance theory (Hoch, Bommer, Dulebohn, \& Wu, 2018), we focus on authentic leadership (AL; Walumbwa, Avolio, Gardner, Wernsing, \& Peterson, 2008) which has, from the outset, been proposed as a 'pathway to positive health' (Ilies, Morgeson, \& Nahrgang, 2005; Macik-Frey, Quick, \& Cooper, 2009).

A few studies have tested this premise, showing that AL is positively related to employees' job satisfaction and negatively related to stress and burnout (Braun \& Peus, 2018; Laschinger \& Fida, 2014; Rahimnia \& Sharifirad, 2015; Walumbwa et al., 2008). However, this research suffers from a number of limitations that impede our understanding of how and when AL predicts employees' health. First, research on AL has, as is the case for the wider 
leadership field (Inceoglu et al., 2018), focused on hedonic, psychological forms of wellbeing. This focus is narrow and provides limited insights because health is comprised of both psychological and physical dimensions (Grant, Christianson, \& Price, 2007) that are intrinsically linked (Ganster \& Rosen, 2013). Given the significant costs associated with, for example, chronic physical illnesses (Buttorff, Ruder, \& Bauman, 2017), research is needed that explores whether AL affects employees' overall health encompassing both physical and mental (psychological) health. Second, the process through which AL contributes to employees' health is not well understood. Although research has revealed mediators (i.e., attachment insecurity and work-life balance; Braun \& Peus, 2018; Rahimnia \& Sharifirad, 2015), important underlying processes risk being overlooked. Specifically, the theoretical rationale for their inclusion can be considered shaky given that their choice was not always informed by AL theory and well-being specific theories (Inceoglu et al., 2018). Last, little is known about the boundary conditions that shape the relationship between AL and health. This is problematic as the effects of leadership have been discussed to vary between individuals (Gooty, Gavin, Gavin, Frazier, \& Snow, 2009), with recent research showing that the health-enhancing effect of transformational leadership is dependent on employees' openness to experience (Hildenbrand, Sacramento, \& Binnewies, 2018). In order to provide meaningful recommendations as to how line managers can promote employee health, it is thus paramount to establish whether this effect applies to all employees or whether AL particularly benefits the health of certain employees.

To contribute towards a better understanding of the AL - health link, we follow Inceoglu et al.'s (2018) call and leverage conservation of resources theory (COR; Hobfoll, 2001), a resource-focused framework. COR posits that individuals have an evolutionary need to acquire and conserve resources because resources are essential for maintaining health and well-being (Hobfoll, Halbesleben, Neveu, \& Westman, 2018). Integrating this framework 
with social information processing theory (SIP; Salancik \& Pfeffer, 1978), we propose that authentic leaders contribute to employees' health through shaping employees' perception of a climate of authenticity (PCA; Grandey, Foo, Groth, \& Goodwin, 2013). While climate of authenticity reflects the extent to which a work group values the expression of authentic emotions (Grandey et al., 2013), we conceptualize it as a psychological climate that reflects employees' perception of their work environment (Kuenzi \& Schminke, 2009), mirroring the conceptualization of resources as per COR according to which their value for individuals' health is subjective (Halbesleben, Neveu, Paustian-Underdahl, \& Westman, 2014). We thus propose that AL shapes the emotional display rules among the employees they supervise such that the expression of authentic and genuine emotions becomes the norm, which should, as a valuable resource, facilitate employees' health. In doing so, we contribute to AL theory through exploring a process, authenticity, which lies at the heart of the AL construct (Avolio \& Gardner, 2005; Lemoine, Hartnell, \& Leroy, 2019), addressing recent concerns regarding the conceptual overlap of positive forms of leadership (Hoch et al., 2018; Lemoine et al., 2019). This also contributes to leadership theory because we explore an emotional pathway that represents an important, but largely neglected, route through which leaders affect employee health (Inceoglu et al., 2018).

Second, we consider employees’ personality, specifically neuroticism (Costa \& McCrae, 1992), as a boundary condition of the mediated relationship between AL and health (second-stage moderation). Individuals high in neuroticism have poorer overall health (Charles, Gatz, Kato, \& Pedersen, 2008) and experience more negative emotions which require emotional regulation (Baumeister, Bratslavsky, Muraven, \& Tice, 1998; Brotheridge \& Lee, 2002) than emotionally stable individuals (Schimmack et al., 2002). Regulating negative emotions is, however, resource-draining and, in line with COR, neurotic individuals should thus benefit from PCA more in regards to their health than emotionally stable 
individuals (Halbesleben et al., 2014) because PCA should constitute a more valuable selfregulatory break for them (Grandey et al., 2013). In proposing neuroticism as a moderator, we contribute to the AL and wider leadership literatures through highlighting that the effects of leadership for employee health are in the 'eyes of the beholder' (Gooty et al., 2009), requiring leaders to consider employees' personality in the way they lead.

Last, we focus on health, comprised of both mental (psychological) and physical health, as an outcome of AL. In doing so, we consider physical health, a largely understudied dimension of health (Inceoglu et al., 2018) which, like psychological health, is influenced by authenticity (Knoll, Meyer, Kroemer, \& Schröder-Abé, 2015) and emotional regulation (Appleton, Buka, Loucks, Gilman, \& Kubzansky, 2013). Accordingly, we advance AL theory through testing whether AL constitutes indeed a pathway to positive health (Macik-Frey et al., 2009) through shaping employees' PCA.

\section{Theory and hypotheses}

COR

COR is a resource-based theory that proposes that humans are motivated to acquire and protect resources because resource loss or threatened resource loss results in health issues (Hobfoll, 2002; Hobfoll \& Freedy, 1993). Initially, resources were defined as encompassing objects, conditions, personal characteristics and energies (Hobfoll, 2002). More recently, the definition has been broadened such that anything that is perceived by individuals as helping them attain their goals constitutes a resource (Halbesleben et al., 2014). As such, the work environment offers various resources (Hobfoll et al., 2018), while their value for individuals and ultimately the extent to which they constitute resources varies between individuals (Halbesleben et al., 2014). A further principle of COR relevant for this study is that individuals who possess resources are in a better position to acquire additional resources 
through investing resources, which results in positive gain spirals. Using COR as an overarching framework, we propose that AL positively affects employees' health through enabling the formation of PCA among the employees they supervise; a resource that contributes to employees' health through reducing employees' need to regulate their emotions.

\section{$A L$ and $P C A$}

Throughout its theoretical development, several definitions of AL have been put forward (see Gardner et al., 2011), the most widely-adopted defining it as "a pattern of leader behaviour that draws upon and promotes both positive psychological capacities and a positive ethical climate, to foster greater self-awareness, an internalized moral perspective, balanced processing of information, and relational transparency on the part of leaders working with followers, fostering positive self-development" (Walumbwa et al., 2008; p. 94). While research has accumulated an impressive evidence base regarding the positive individual and organizational outcomes of AL (e.g., Banks, McCauley, Gardner, \& Guler, 2016; Hoch, Bommer, Dulebohn, \& Wu, 2018), recent calls have been made for research to devise hypothesized models around the core essence of the respective leadership construct to meaningfully contribute to theory (Hoch et al., 2018; Lemoine et al., 2019).

$\mathrm{AL}$ is grounded in theories of authenticity (Avolio \& Gardner, 2005; Ilies et al., 2005; Kernis \& Goldman, 2006), the alignment between individuals' internal sense of self and their outward-facing behaviours (Cha et al., 2019). Given that authenticity has long been regarded as critical for good health (Erickson, 1995) and lies at the heart of AL (Lemoine et al., 2019), we regard authenticity, specifically PCA, as the key mechanism through which AL affects employees' health. 
According to COR, good leadership can be considered a valuable resource for employees that also contributes to their resource repertoire through sending social cues that influence their ability to acquire further resources (Hobfoll, 2002; Inceoglu et al., 2018). The notion of leaders shaping employees' beliefs about their work environment is supported by SIP (Salancik \& Pfeffer, 1978), according to which individuals' perceptions, attitudes and behaviours are influenced by cues from their social context (Zalesny \& Ford, 1990). Due to their position power, leaders hold a central role in this influencing process and signal, through their behavior and overt statements, what constitutes acceptable and desirable behavior (Hogg, Rast, \& van Knippenberg, 2012).

Integrating COR with SIP, we posit that authentic leaders shape employees' beliefs about their work environment, enabling the formation of a PCA among the employees they supervise. Central to AL is the expression of authentic feelings, thoughts and emotions (Lehman et al., 2019; Lemoine et al., 2019). Authentic leaders' behaviour and their transparent display of genuine felt emotions (Gardner et al., 2009) should thus signal to employees that such authentic expression is the norm (Cha et al., 2019). In doing so, they set the tone for followers' genuine emotional expression during their daily interpersonal interactions not only with their leader, but also with their work group (Avolio \& Gardner, 2005; Gardner, Avolio, Luthans, May, \& Walumbwa, 2005). As a result, employees should perceive their group members as accepting of the expression of emotions and feelings, including negative ones (Grandey et al., 2013), as reflected by PCA (Grandey et al., 2013). Given that the value of resources is subjective and varies between individuals (Halbesleben et al., 2014), we conceptualize PCA as a psychological climate reflecting employees' perception of their work group (Kuenzi \& Schminke, 2009). We therefore hypothesize:

H1. AL is positively related to PCA. 


\section{PCA and employee health}

Research has moved away from the dualism that considers the mind and body as distinct entities, acknowledging that psychological and physical health are intrinsically linked (Song et al., 2015). Emotions and emotional regulation have been discussed as a common thread that connects both (Adler \& Matthews, 1994). Research offers evidence that supports this claim insofar that authenticity and displaying authentic emotions is beneficial for both psychological and physical health, while suppressing felt emotions is harmful (Appleton et al., 2013; Cloitre et al., 2019; Grandey, 2003; Ménard \& Brunet, 2011). Consequently, we regard PCA as positively related to employees' health.

This proposition is in line with COR (Hobfoll, 2002). Specifically, expressing felt emotions, such as sadness, frustration and joy, enables employees to conserve and replenish the attentional and energy resources they would normally invest into monitoring and regulating said emotions (Baumeister et al., 1998; Baumeister, Vohs, \& Tice, 2007; Muraven, Shmueli, \& Burkley, 2006) and thus represents a self-regulatory break (Grandey et al., 2013). Additionally, employees who feel able to exhibit their true emotions and whose outward expression is thus aligned with their true self should also benefit from establishing meaningful connections with their coworkers, giving them access to the resources the group offers (Emmerich, Knoll, \& Rigotti, 2020). For example, employees who share their struggles concerning a specific work task with their coworkers should receive help from them, constituting additional resources that protect their health (Hobfoll, 2002). We thus hypothesize:

H2. PCA is positively related to employee health.

The mediating role of $P C A$ 
Combining the previous hypotheses, we propose that through expressing authentic emotions, authentic leaders set the contextual standard for the expression of genuine emotions in the group of employees they supervise (Cha et al., 2019; Salancik \& Pfeffer, 1978), influencing emotional display rules in a top-down fashion (Grandey et al., 2013). Employees who perceive their workgroup as enabling them to express their true emotions (PCA) need to invest less attentional and energy resources into regulating their emotions (Baumeister et al., 1998), while also benefitting from social resources from their work group brought about by sharing their true needs and concerns (Emmerich et al., 2020). Such employees should thus benefit from an increased pool of resources that positively contributes to their health (Baumeister et al., 1998; Hobfoll, 2002). We thus hypothesize:

H3. PCA mediates the relationship between AL and employee health.

\section{Study 1}

\section{Method}

A total of 104 employees from two German companies $\left(72.1 \%\right.$ female, $M_{\text {age }}=42.63, S D=$ 9.62, $M_{\text {tenure }}=10.62, S D=8.32$ ) completed online (pharmaceutical company; $n=72$ ) or paper surveys (geriatric care company; $n=32$ ) at two time points (Time 1 and Time 2), four weeks apart. The response rate was $74 \%$. All participants worked in teams $\left(M_{\text {team-tenure }}=6.6\right.$, $S D=6.3)$

The surveys were administered in German. Official translations were used where available. We translated the items for PCA using standard procedures of back-translation (Brislin, 1980). Apart from health, all items were scored on a 5-point Likert scale $(1=$ strongly disagree to $5=$ strongly agree).

$$
A L(\alpha=.94) \text { was measured at Time } 1 \text { with the official German translation }
$$

(Mindgarden, Inc.) of Walumbwa et al.'s (2008) 16-item scale (e.g., "My leader is eager to receive feedback to improve interactions with others"). Previous research has concluded that 
regarding AL as a higher-order factor encompassing the four AL dimensions of selfawareness, relational transparency, balanced processing, and internalized moral/ethical perspective is justified (Avolio, Wernsing, \& Gardner, 2018). CFAs also supported the use of a composite score over a dimensional approach. ${ }^{1}$ In line with our conceptualization of PCA along COR as a resource whose value is subjective (Halbesleben et al., 2014) and research that assesses perceived team/organizational climate at the individual level (e.g., Baker, 2016; Zhou, Liu, Chen, \& Zhao, 2018), we measured employees' perceptions of climate of authenticity at Time $1(\alpha=.82)$ with Grandey et al.'s (2013) 7-item measure (e.g., "Working with members of this team, expressions of feelings are respected"). We measured health over the past four weeks at Time 2 using the German version of the SF-12-item Health Survey (Ware, Kosinski, \& Keller, 1996), a measure extensively used in research, particularly in medical sciences (Brazier \& Roberts, 2004). The scale covers physical (e.g., "Have you accomplished less than you would like as a result of your physical health?”) and mental health (e.g., "Have you felt peaceful and calm?"). We used the official scoring software² (Health Outcomes Scoring Software 4.0 by QualityMetric) to compute an overall health score; a high score reflects good health. In line with past research (Frone et al., 1996; Little et al., 2007; Brown et al., 2016), we controlled for positive (e.g., "inspired”, $\alpha=.86$ ) and negative affect (e.g., "upset", $\alpha=.75$ ) over the past four weeks, which we measured at Time 2 with the shortened 10-item PANAS scale (Thompson, 2007); participant age, gender (1=

\footnotetext{
${ }^{1}$ The CFA for the second-order model for AL fit the data equally well $(\chi 2(98)=267.44, p<.01, \mathrm{CFI}=.88$, TLI $=.85, \mathrm{RMSEA}=.11, \mathrm{SRMR}=.07)$ as the 4-factor model $(\chi 2(100)=170.53, \mathrm{p}<.01, \mathrm{CFI}=.88, \mathrm{TLI}=.85$, RMSEA $=.11$, SRMR $=.07$ ). To compare the two models, we used the Bayesian information criterion (BIC) where a better fit is indicated by a smaller BIC (Schreiber, Stage, King, Nora, \& Barlow, 2006). The BIC of 5484.64 of the second-order model supports its use over the four-factor model $(\mathrm{BIC}=5491.64)$.

${ }^{2}$ Response options for the SF-12 differ per item and include, for example, (1) 'yes, limited a lot' to (3) 'no, not limited at all'. Under Optuminsight Life Sciences's (Qualitymetric) terms, any changes, including formatting changes, are required to be stated. Accordingly, we independently introduced a minor change to the response format of item number 12 (During the past 4 weeks, how much of the time has your physical health or emotional problems interfered with your social activities?) from a 6-point to a 5-point scale, in line with other response items in the SF-12. Given this slightly deviates from the original survey, it is possible that validity and reliability indices are affected. However, this deviation did not undermine the psychometric properties of our measure $(\alpha=$ .70 for Study $1 ; \alpha=.76$ for Study 2).
} 
male, 2 =female $)$ and company $(1=$ pharmaceutical company; 2 = geriatric care company $)$ given that employees in the geriatric care company worked part-time and employees in the pharmaceutical company full-time. CFAs showed that the hypothesized 3-factor model $\left(\chi^{2}(554)=649.55, p<.01, \mathrm{CFI}=.92, \mathrm{TLI}=.92, \mathrm{RMSEA}=.03, \mathrm{SRMR}=.09\right)$ fit the data better than a 2 -factor $\left(\chi^{2}(560)=881.92, p<.01, \mathrm{CFI}=.73, \mathrm{TLI}=.72, \mathrm{RMSEA}=.06, \mathrm{SRMR}\right.$ $=.13)$ or 1 -factor solution $\left(\chi^{2}(560)=1384.45, p<.01, \mathrm{CFI}=.33, \mathrm{TLI}=.28, \mathrm{RMSEA}=.1\right.$, $\operatorname{SRMR}=.21)$

\section{Results}

Table I displays descriptives and correlations and Table II the findings. We used the Process macro for SPSS (Hayes, 2017) to test the hypotheses and 10,000 bootstrapping samples with $95 \%$ confidence intervals $(\mathrm{CI})$ to test the indirect effects.

Insert Table I about here

The results showed that AL was significantly and positively related to PCA ( $B=.23, S E$ $=.06, p<.01)$, as was PCA to health $(B=2.94, S E=.86, p<.01)$. AL had an indirect positive effect on health through PCA (indirect effect $=.64, S E=.34 ; 95 \% \mathrm{CI}[.08 ; 1.41]$ ), providing support for $H 1-H 3$.

Insert Table II about here

\section{Study 2}

This study aimed to provide a constructive replication of the findings of Study 1 (Hüffmeier et al., 2016) by extending the model to test the moderating role of neuroticism. 
A tenet of COR that has recently been emphasized is that the value of resources is subjective and their effect thus depends on their interplay with individual differences (Halbesleben et al., 2014). Neuroticism, individuals' tendency to experience negative emotions, such as anxiety and self-doubt (Costa \& McCrae, 1992), seems particularly relevant in this regard as it is a strong negative predictor of health (Charles et al., 2008; Costa $\&$ McCrae, 1980). Negative emotions are rarely desirable within organizations (Schaubroeck \& Jones, 2000), and employees high in neuroticism often engage in resource-draining emotional regulation, particularly in the form of suppressing felt emotions (Diefendorff, Croyle, \& Gosserand, 2005), which is particularly detrimental for health, both physically and psychologically (Appleton et al., 2013; Baumeister et al., 2007). Individuals high in neuroticism should thus benefit more from PCA as a resource than emotionally stable employees because being able to express authentic emotions represents more of a valued selfregulatory break for them (Grandey et al., 2013), affecting their health to a greater extent. We therefore hypothesize:

H4. Employee neuroticism moderates the positive effect of PCA on employee health, such that the effect is stronger when neuroticism is high rather than low.

Integrating H1-H4 that relied on COR (Hobfoll, 2002) and SIP (Salancik \& Pfeffer, 1978), we argue that the positive effect of AL on employee health via PCA is dependent on employees' neuroticism. Specifically, we propose that authentic leaders' signals to express true and genuine emotions result in employees' perception of PCA, which should positively affect the health of employees high as opposed to low in neuroticism. This is because we contend that PCA constitutes a more valuable resource for these employees (Halbesleben et al., 2014) as it reduces their need to regulate their surplus of negative emotions in interpersonal interactions (Schimmack et al., 2002), which is predictive of health (Appleton et al., 2013; Baumeister et al., 2007). We therefore hypothesize: 
H5. The indirect effect of AL on employee health through PCA is moderated by employee neuroticism in the second stage such that the positive relationship between PCA and employee health will be stronger when neuroticism is high rather than low.

\section{Study 2}

\section{Method}

A total of 146 working adults $\left(62.3 \%\right.$ male, $M_{\text {age }}=30.34, S D=8.00, M_{\text {tenure }}=5.00, S D=$ 4.80), recruited via the German crowdsourcing website workhub.de (now www.crowdworker.com), completed an online survey at two time points (Time 1 and 2), four weeks apart. The response rate was $63.2 \%$ and participants were reimbursed $€ 2(\$ 2.25)$ per survey. All participants included in the sample had passed Instructional Manipulation Checks (Oppenheimer et al., 2009), worked full-time in a group-based work setting and were fluent in German. They worked in a variety of jobs, such as clerical, military officer and paralegal.

The same measures and controls as in Study 1 were used in Study 2 at Time $1(A L(\alpha$ $\left.=.95^{3}\right), P C A(\alpha=.77)$, positive $(\alpha=.86)$, and negative affect $(\alpha=.81)$, gender, age $)$ and Time 2 (health). Neuroticism $(\alpha=.70)$ was measured at Time 1 with three items taken from Judge et al.'s (2003) core self-evaluations scale (e.g., "Sometimes I feel depressed"; 1 = strongly disagree to $5=$ strongly agree). CFAs showed that the proposed 4 -factor model ${ }^{4}$ $\left(\chi^{2}(659)=1361.25, p<.01, \mathrm{CFI}=.88, \mathrm{TLI}=.87, \mathrm{RMSEA}=.08, \mathrm{SRMR}=.08\right)$ fit the data better than a 3 -factor $\left(\chi^{2}(662)=1945.75, p<.01, \mathrm{CFI}=.77, \mathrm{TLI}=.75, \mathrm{RMSEA}=.11\right.$,

\footnotetext{
${ }^{3}$ The CFA for the second-order model for AL showed a superior fit $(\chi 2(98)=180.47, \mathrm{p}<.01, \mathrm{CFI}=.95, \mathrm{TLI}=$ $.93, \mathrm{RMSEA}=.07, \mathrm{SRMR}=.04, \mathrm{BIC}=6130.781)$ than the 4-factor $\operatorname{model}(\chi 2(100)=183.100, \mathrm{p}<.01, \mathrm{CFI}=$ $.95, \mathrm{TLI}=.93, \mathrm{RMSEA}=.07, \mathrm{SRMR}=.04, \mathrm{BIC}=6138.118)$ when the BIC was considered (Schreiber et al., 2006).

${ }^{4}$ Although some of our fit indices (CFI, TLI) are slightly below the recommended cut-off scores, this is likely due to our small sample size $(n<250 ; \mathrm{Hu} \&$ Bentler, 1999; Marsh et al., 2004). In line with the recommendation of Marsh et al., (2004), we thus assessed the adequacy of our model in comparison to alternative models.
} 
$\mathrm{SRMR}=.1)$ and 1 -factor model $\left(\chi^{2}(665)=3276.92, p<.01, \mathrm{CFI}=.53, \mathrm{TLI}=.51, \mathrm{RMSEA}=\right.$ $.16, \mathrm{SRMR}=.14)$.

\section{Results}

Table I displays descriptives and correlations and Table II the findings. We followed the same analytical procedures as in Study 1. $H 4$ and $H 5$ were tested using the Process macro for SPSS for Model 4 and 14 (Hayes, 2017). Simple slope tests were used to probe for the direction of the interaction (Dawson, 2014) and the moderated mediation effects were tested using 10,000 bootstrapping samples with 95\% CI.

Consistent with Study 1, AL was significantly and positively related to PCA $(B=.16, S E$ $=.05, p<.01)$, as was PCA to health $(B=1.79, S E=.68, p<.01)$. Again, AL had an indirect positive effect on health through PCA (indirect effect $=.28, S E=.17 ; 95 \%$ CI $[.01 ; .69]$ ), supporting $H 1-H 3$. The interaction between PCA and neuroticism on health was significant (Figure $1 ; B=2.07, S E=.75, p<.01$ ). Simple slope tests showed that this effect was not significant for low $(-1 \mathrm{SD} ; b=-.02, S E=.89, p=.98)$, but positive and significant for high levels of neuroticism $(+1 \mathrm{SD} ; b=3.43, S E=.93, p<.01)$, supporting $H 4$.

Insert Figure 1 about here

The index of moderated mediation was significant (index: .36, 95\% CI $[.06 ; .80]$ ). The results showed non-significant effects under -1SD of neuroticism (conditional indirect effect: $-.05,95 \% \mathrm{CI}[-.36 ; .21]$ ), but significant moderated mediation under $+1 \mathrm{SD}$ (conditional indirect effect: .55, 95\% CI $[.11 ; 1.21)$, supporting $H 5$.

\section{General discussion}

This research aimed to explore how and for whom AL is positively related to health. The findings of both studies showed that PCA transmitted the positive influence of AL onto 
employee health, while Study 2 additionally showed that this indirect effect was moderated by employees' neuroticism (second-stage mediated moderation).

\section{Theoretical implications}

We believe that our research contributes to the existing AL and wider leadership literatures in three ways. First, while prior research has explored the ins and outs of the effect of AL on health and well-being to some extent (Braun \& Peus, 2018; Rahimnia \& Sharifirad, 2015), the studied underlying processes (i.e. work-life balance and attachment insecurity) do not reflect what lies at the core of AL and do thus not test AL theory. This point reflects criticism the leadership field has recently faced regarding conceptual overlap of positive leadership constructs and lack of conceptual differentiation (Hoch et al., 2018; Lemoine et al., 2019), and the use of theories primarily devised for job performance to explain effects on health (Inceoglu et al., 2018). We address these limitations through using COR (Halbesleben et al., 2014; Hobfoll, 2002) as a framework, which we supplement with SIP (Salancik \& Pfeffer, 1978) to identify PCA (Grandey et al., 2013), employees' perception that their work group values the expression of authentic emotions, as a mediator of the relationship between AL and employee health. In doing so, we highlight that authenticity, driven by leaders' ability to shape norms linked to authentic emotional display, constitutes a core pathway that explains the health-promoting effect of AL.

Second, we explored employees' neuroticism, their tendency to experience negative emotions (Costa \& McCrae, 1992), as a boundary condition that shapes the effect of AL on employees' health via PCA. While prior research has shown that the effects of AL on performance are dependent on followers' individual differences (i.e. psychological capital; Wang, Sui, Luthans, Wang, \& Wu, 2014), it is not known whether this is also true for the effect of AL on employee health. Leveraging COR (Halbesleben et al., 2014; Hobfoll, 2002), 
we show that PCA, a resource enabled by AL, is particularly beneficial for employees high in neuroticism, with those low in neuroticism not exhibiting increased health. These findings reflect leadership as a relational process (Uhl-Bien, 2006) that involves both leaders and followers as active participants. As such, we contribute to the AL and wider leadership literatures through highlighting that leaders' effect on employees' health is contingent on followers' characteristics (Gooty et al., 2009), specifically their neuroticism, and thus varies between employees depending on the purpose it serves.

Finally, through focusing on health as comprised of both mental (psychological) and physical health, we contribute to the AL literature, which has, mirroring the wider leadership literature, narrowly operationalized health through hedonic, psychological health (e.g., job satisfaction and burnout; Inceoglu et al., 2018). This is problematic insofar that it is widely acknowledged that psychological and physical health are intrinsically linked (Song et al., 2015) and both facets need to be captured to provide a full picture. We thus contribute to AL theory through showing that AL does represent a pathway to overall, positive health (MacikFrey et al., 2009) and not a tradeoff between either psychological or physical health as is the case for other managerial practices (Grant et al., 2007).

\section{Limitations and future research directions}

Our contributions need to be interpreted in light of the following limitations. First, we collected data solely from employees as their perceptions, as opposed to others' perceptions, should determine whether AL and PCA constitute resources that can affect well-being (Halbesleben et al., 2014); potentially a reason why the majority of research on leadership and well-being relies on employees' perspective (Inceoglu et al., 2018). However, our research thus bears the risk of common method bias (Podsakoff, MacKenzie, Lee, \& Podsakoff, 2003). While we tried to minimize this risk through replicating our findings across two studies, temporarily separating predictor and outcome variables and conducting 
Harman's single factor tests (CFAs), we cannot fully exclude the effect of common method bias on our findings. Additionally, because we did not employ a cross-lagged design to test for mediation, we cannot exclude reverse causality.

Second, data for both studies was collected in Germany and, in Study 2, via crowdsourcing; two factors that might affect the generalizability of our findings. While previous research has shown that the effect of AL transcends national cultures (Gardner et al., 2011), emotion regulation and the extent to which authentic emotional expression are valued and can thus affect health have been discussed as depending on national culture, specifically the cultural dimension of independence (Ford \& Mauss, 2015). Additionally, crowdsourcing samples have been shown to differ from the general population, specifically regarding their average age and level of education (Paoslacci, Chandler, \& Ipeirotis, 2010). However, crowdsourced testing is beneficial because it can help to reveal the true consistency of empirical support for a model (Landy et al., 2020) and therefore represents an adequate replication and extension of Study 1.

Third, in line with COR and the notion that the value and thus usefulness of resources for health varies between individuals (Halbesleben et al., 2014), we regarded PCA as a psychological climate that reflects employees' perception of their work environment (Kuenzi \& Schminke, 2009). While this approach is not uncommon (e.g., Baker, 2016; Zhou, Liu, Chen, \& Zhao, 2018), climate of authenticity has been conceptualized as a group-level construct (Grandey et al., 2013) and our research can, as such, not providing insights regarding groups' shared climate of authenticity.

Given these limitations, we encourage future research to replicate our findings. Specifically, to further reduce common method and common source bias, future studies might want to adopt cross-lagged designs, nested multilevel designs and consider alternative measures for physical health, such as wearable technology (Inceoglu et al., 2018). 
Conducting such research in a considerably different cultural context to our study (e.g., interdependent context, such as East Asia; Ford \& Mauss, 2015) seems also a worthwhile endeavor. We believe that future research has the potential to expand our understanding of the relationship between leadership and health further if, as exemplified in our study, health and well-being specific theories are leveraged (Inceoglu et al., 2018). Specifically, selfdetermination theory (Deci et al., 2001) or the work-home resource model (ten Brummelhuis \& Bakker, 2012) might offer insights into the resources leaders provide employees with and into employee characteristics that determine the value of these resources for their health (Halbesleben et al., 2014). Research along these lines might, for example, explore how leader behaviors specific to AL, such as sharing genuine emotions, affect employees' health through satisfying employees' needs, which are determined by their individual differences, such as their need for relatedness. Furthermore, the development of our hypothesized model was guided by an effort to capture what lies at the core of AL (Lemoine et al., 2019), which we regarded to be authenticity and the expression of genuine emotions (Gardner et al., 2005), leading us to explore PCA as an emotional pathway. We recommend that, in order to contribute to AL theory, future research on AL and health also adopts such an approach and explores, for example, the behavioral pathways of role modeling or behavioral integrity. Last, while we focused on PCA as a psychological climate (Kuenzi \& Schminke, 2009), we have reason to assume that climate of authenticity represents an important contextual, team-level resource that shapes employees' health and well-being (Grandey et al., 2013). We thus encourage future research to employ a multilevel design to test this proposition.

\section{Practical implications}

Our findings have several implications for practice. First, AL represents a useful tool organizations can leverage to maintain a healthy workforce. Importantly, given the positive indirect effect of AL on health comprised of both mental (psychological) and physical health, 
it does not represent a trade-off between different forms of health either, as is the case for other managerial practices, such as work redesign (Grant et al., 2007). Organizations can reap these benefits of AL through selecting/recruiting authentic leaders for key positions, using AL assessments (Neider \& Schriesheim, 2011; Walumbwa et al., 2008), or through developing authentic leaders through AL training (Baron, 2016), which is particularly relevant when employees' work is highly demanding and staff suffer from poor health.

Second, line managers should encourage work groups to express and be accepting of the expression of authentic emotions, facilitating a PCA through encouraging authentic emotional display norms. This seems particularly relevant in contexts where employees' work involves frequent, emotionally draining interpersonal interactions and where employees are subjected to negative emotions that require emotional labor, such as in customer-facing or caring roles (Grandey et al., 2013). Additionally, team-building interventions may contribute to team members forming meaningful relationships that provide them with the space to be their true selves without facing repercussions and enable them to share their true emotions regularly, for example, during shared work breaks. On an organizational level, sharing and valuing others' emotions can be supported through, for example, Schwartz Rounds, a relatively low-cost intervention mainly used in healthcare organizations (Schwartz Rounds, 2020).

Last, given that AL and PCA seem to be particularly beneficial for the health of neurotic employees, facilitating PCA in work groups with neurotic members through the discussed means is specifically important. This is of relevance if organizations and line managers aim to facilitate inclusive workplaces that accommodate individuals with mental health issues, such as depression, which individuals high in neuroticism are more susceptible to (Hirschfeld, Cole, Bernerth, \& Rizzuto, 2013). Fostering PCA through AL would ensure that employees have a fundamental support system in place that they can reach out to. 


\section{Reference list}

Adler, N., \& Matthews, K. (1994). Health psychology: Why do some people get sick and some stay well? Annual Review of Psychology, 45, 229-259.

Appleton, A. A., Buka, S. L., Loucks, E. B., Gilman, S. E., \& Kubzansky, L. D. (2013). Divergent associations of adaptive and maladaptive emotion regulation strategies with inflammation. Health Psychology, 32(7), 748-756.

Avolio, B. J., \& Gardner, W. L. (2005). Authentic leadership development: Getting to the root of positive forms of leadership. The Leadership Quarterly, 16(3), 315-338.

Avolio, B. J., Wernsing, T., \& Gardner, W. L. (2018). Revisiting the Development and Validation of the Authentic Leadership Questionnaire: Analytical Clarifications. Journal of Management, 44(2), 399-411.

Baker, A. N. (2016). Antecedents and consequences of observing workplace sexual behavior. Journal of Managerial Psychology, 31(1), 265-279.

Banks, G. C., McCauley, K. D., Gardner, W. L., \& Guler, C. E. (2016). A meta-analytic review of authentic and transformational leadership: A test for redundancy. Leadership Quarterly, 27(4), 634-652.

Baron, L. (2016). Authentic leadership and mindfulness development through action learning. Journal of Managerial Psychology, 31(1), 296-311.

Bass, B. M. (1985). Leadership and performance beyond expectations. New York: The Free Press.

Baumeister, R. F., Bratslavsky, E., Muraven, M., \& Tice, D. M. (1998). Ego depletion: Is the active self a limited resource? Journal of Personality and Social Psychology, 74(5), $1252-1265$. 
Baumeister, R. F., Vohs, K. D., \& Tice, D. M. (2007). The strength model of self-control. Current Directions in Psychological Science, 16(6), 351-355.

Braun, S., \& Peus, C. (2018). Crossover of Work-Life Balance Perceptions: Does Authentic Leadership Matter? Journal of Business Ethics, 149(4), 875-893.

Brazier, J., \& Roberts, J. (2004). The estimation of a preference-based measures of health from the SF-12. Medical Care, 42, 851-859.

Brislin, R. W. (1980). Translation and content analysis of oral and written material. In H. C. Triandis \& J. W. Berry (Eds.), Handbook of cross-cultural psychology (2nd ed., pp. 349-444). Boston: Allyn and Bacon.

Brotheridge, C. M., \& Lee, R. T. (2002). Testing a conservation of resources model of the dynamics of emotional labor. Journal of Occupational Health Psychology, 7(1), 57-67.

Brown, T. H., Richardson, L. J., Hargrove, T. W., \& Thomas, C. S. (2016). Using Multiplehierarchy Stratification and Life Course Approaches to Understand Health Inequalities: The Intersecting Consequences of Race, Gender, SES, and Age. Journal of Health and Social Behavior, 57(2), 200-222.

Buttorff, C., Ruder, T., \& Bauman, M. (2017). Multiple Chronic Conditions in the United States. Retrieved December 7, 2020, from https://sbgg.org.br/informativos/29-0617/1497877975_1_Chronic_Conditions.pdf

Cha, S. E., Hewlin, P. F., Roberts, L. M., Buckman, B. R., Leroy, H., Steckler, E. L., ... Cooper, D. (2019). Being your true self at work: Integrating the fragmented research on authenticity in organizations. Academy of Management Annals, 13(2), 633-671.

Charles, S. T., Gatz, M., Kato, K., \& Pedersen, N. L. (2008). Physical health 25 years later: The predictive ability of neuroticism. Health Psychology, 27(3), 369-378. 
Cloitre, M., Khan, C., Mackintosh, M.-A., Garvert, D. W., Henn-Haase, C. M., Falvey, E. C., \& Saito, J. (2019). Emotion regulation mediates the relationship between ACES and physical and mental health. Psychological Trauma: Theory, Research, Practice, and Policy, 11(1), 82-89.

Costa, P. T., \& McCrae, R. R. (1980). Influence of extraversion and neuroticism on subjective well-being: Happy and unhappy people. Journal of Personality and Social Psychology, 38(4), 668-678.

Costa, P. T., \& McCrae, R. R. (1992). Four ways five factors are basic. Personality and Individual Differences, 13(6), 653-665.

Dawson, J. F. (2014). Moderation in management research: What, why, when, and how. Journal of Business and Psychology, 29(1), 1-19.

Diefendorff, J. M., Croyle, M. H., \& Gosserand, R. H. (2005). The dimensionality and antecedents of emotional labor strategies. Journal of Vocational Behavior, 66(2), 339357.

Emmerich, A. I., Knoll, M., \& Rigotti, T. (2020). The authenticity of the others: How teammates' authenticity relates to our well-being. Small Group Research, 51(2), 175207.

Erickson, R. J. (1995). The Importance of Authenticity for Self and Society. Symbolic Interaction, 18(2), 121-144.

Ford, B. Q., \& Mauss, I. B. (2015). Culture and emotion regulation. Current Opinion in Psychology, 3, 1-5.

Foreman, K. J., Marquez, N., Dolgert, A., Fukutaki, K., Fullman, N., McGaughey, M., ... Murray, C. J. L. (2018). Forecasting life expectancy, years of life lost, and all-cause and 
cause-specific mortality for 250 causes of death: reference and alternative scenarios for 2016-40 for 195 countries and territories. The Lancet, 392(10159), 2052-2090.

Frone, M. R., Russell, M., \& Barnes, G. M. (1996). Work-family conflict, gender, and healthrelated outcomes: a study of employed parents in two community samples. Journal of Occupational Health Psychology, 1(1), 57-69.

Ganster, D. C., \& Rosen, C. C. (2013). Work Stress and Employee Health. Journal of Management, 39(5), 1085-1122.

Gardner, W. L., Avolio, B. J., Luthans, F., May, D. R., \& Walumbwa, F. (2005). “Can you see the real me?" A self-based model of authentic leader and follower development. Leadership Quarterly, 16(3), 343-372.

Gardner, W. L., Cogliser, C. C., Davis, K. M., \& Dickens, M. P. (2011). Authentic leadership: A review of the literature and research agenda. Leadership Quarterly, 22(6), $1120-1145$.

Gardner, W. L., Fischer, D., \& Hunt, J. G. (Jerry. (2009). Emotional labor and leadership: A threat to authenticity? Leadership Quarterly, 20(3), 466-482.

Goetzel, R. Z., Long, S. R., Ozminkowski, R. J., Hawkins, K., Wang, S., \& Lynch, W. (2004). Health, Absence, Disability, and Presenteeism Cost Estimates of Certain Physical and Mental Health Conditions Affecting U.S. Employers. Journal of Occupational and Environmental Medicine, 46(4), 398-412.

Gooty, J., Gavin, M., Gavin, M., Frazier, L. M., \& Snow, B. D. (2009). In the eyes of the beholder: Transformational leadership, positive psychological capital, and performance. Journal of Leadership and Organizational Studies, 15(4), 353-367.

Grandey, A. A. (2003). When "the show must go on": Surface acting and deep acting as 
determinants of emotional exhaustion and peer-rated service delivery. Academy of Management Journal, 46(1), 86-96.

Grandey, A. A., Foo, S. C., Groth, M., \& Goodwin, R. E. (2013). Free to be you and me: A climate of authenticity alleviates burnout from emotional labor. Journal of Occupational Health Psychology, 17(1), 1-14.

Grant, A. M., Christianson, M. K., \& Price, R. H. (2007). Happiness, health, or relationships? Managerial practices and employee well-being tradeoffs. Academy of Management Perspectives, 21(3), 51-63.

Guest, D. E. (2017). Human resource management and employee well-being: towards a new analytic framework. Human Resource Management Journal, 27(1), 22-38.

Halbesleben, J. R. B., Neveu, J. P., Paustian-Underdahl, S. C., \& Westman, M. (2014). Getting to the "COR": Understanding the role of resources in conservation of resources theory. Journal of Management, 40(5), 1334-1364.

Hammer, L. B., \& Zimmerman, K. L. (2011). Quality of work life. In S. Zedeck (Ed.), American Psychological Association handbook of industrial and organizational psyc

Hayes, A. F. (2017). Introduction to mediation, moderation, and conditional process analysis: A regression-based approach (2nd ed.). New York, NY: Guilford Press.

Hildenbrand, K., Sacramento, C. A., \& Binnewies, C. (2018). Transformational leadership and burnout: The role of thriving and followers' openness to experience. Journal of Occupational Health Psychology, 23(1), 31-43.

Hirschfeld, R. R., Cole, M. S., Bernerth, J. B., \& Rizzuto, T. E. (2013). Voluntary survey completion among team members: Implications of noncompliance and missing data for multilevel research. Journal of Applied Psychology, 98(3), 454-468. 
Hobfoll, S. E. (2001). The influence of culture, community, and the nested-self in the stress process: Advancing conservation of resources theory. Applied Psychology, 50(3), 337421.

Hobfoll, S. E. (2002). Social and Psychological Resources and Adaptation. Review of General Psychology, 6(4), 307-324.

Hobfoll, S. E., \& Freedy, J. (1993). Conservation of resources: A general stress theory applied to burnout. In W. B. Schaufeli, C. Maslach, \& T. Marek (Eds.), Series in applied psychology: Social issues and questions. Professional burnout: Recent developments in theory and research (pp. 115-133). Taylor \& Francis.

Hobfoll, S. E., Halbesleben, J., Neveu, J. P., \& Westman, M. (2018). Conservation of resources in the organizational context: The reality of resources and their consequences. Annual Review of Organizational Psychology and Organizational Behavior, 5, 103-128.

Hoch, J. E., Bommer, W. H., Dulebohn, J. H., \& Wu, D. (2018). Do ethical, authentic, and servant leadership explain variance above and beyond transformational leadership? A meta-analysis. Journal of Management, 44(2), 501-529.

Hogg, M. A., Rast, D. E., \& van Knippenberg, D. (2012). The social identity theory of leadership: Theoretical origins, Research findings, And conceptual developments. European Review of Social Psychology, 23(1), 258-304.

Hu, L. T., \& Bentler, P. M. (1999). Cutoff criteria for fit indexes in covariance structure analysis: Conventional criteria versus new alternatives. Structural Equation Modeling: A Multidisciplinary Journal, 6(1), 1-55.

Hüffmeier, J., Mazei, J., \& Schultze, T. (2016). Reconceptualizing replication as a sequence of different studies: A replication typology. Journal of Experimental Social Psychology, 
$66,81-92$.

Ilies, R., Morgeson, F. P., \& Nahrgang, J. D. (2005). Authentic leadership and eudaemonic well-being: Understanding leader-follower outcomes. Leadership Quarterly, 16(3), 373394.

Inceoglu, I., Thomas, G., Chu, C., Plans, D., \& Gerbasi, A. (2018). Leadership behavior and employee well-being: An integrated review and a future research agenda. Leadership Quarterly, 29(1), 179-202.

Judge, T. A., Erez, A., Bono, J. E., \& Thoresen, C. J. (2003). The core self-evaluations scale: Development of a measure. Personnel Psychology, 56, 303-331.

Kernis, M. H., \& Goldman, B. M. (2006). A multicomponent conceptualization of authenticity: Theory and research. In M. P. Zanna (Ed.), Advances in experimental social psychology (pp. 283-357). Academic Press.

Knoll, M., Meyer, B., Kroemer, N. B., \& Schröder-Abé, M. (2015). It Takes Two to Be Yourself. Journal of Individual Differences, 36(1), 38-53.

Kuenzi, M., \& Schminke, M. (2009). Assembling Fragments Into a Lens: A Review, Critique, and Proposed Research Agenda for the Organizational Work Climate Literature. Journal of Management, 35(3), 634-717.

Landy, J. F., Jia, M. (Liam), Ding, I. L., Viganola, D., Tierney, W., Dreber, A., ... Uhlmann, E. L. (2020). Crowdsourcing hypothesis tests: Making transparent how design choices shape research results. Psychological Bulletin, 146(5), 451-479.

Laschinger, H. K. S., \& Fida, R. (2014). A time-lagged analysis of the effect of authentic leadership on workplace bullying, burnout, and occupational turnover intentions. European Journal of Work and Organizational Psychology, 23(5), 739-753. 
Lehman, D. W., O’Connor, K., Kovács, B., \& Newman, G. E. (2019). Authenticity. Academy of Management Annals, 13(1), 1-42.

Lemoine, G. J., Hartnell, C. A., \& Leroy, H. (2019). Taking stock of moral approaches to leadership: An integrative review of ethical, authentic, and servant leadership. Academy of Management Annals, 13(1), 148-187.

Little, L. M., Simmons, B. L., \& Nelson, D. L. (2007). Health among leaders: Positive and negative affect, engagement and burnout, forgiveness and revenge. Journal of Management Studies, 44(2), 243-260.

Macik-Frey, M., Quick, J. C., \& Cooper, C. L. (2009). Authentic leadership as a pathway to positive health. Journal of Organizational Behavior, 30(3), 453-458.

Marsh, H. W., Hau, K.-T., \& Wen, Z. (2004). Structural equation modeling : A modeling latent growth curves with incomplete data using different types of structural equation modeling and multilevel software. Structural Equation Modeling, 11(3), 452-483.

Ménard, J., \& Brunet, L. (2011). Authenticity and well-being in the workplace: a mediation model. Journal of Managerial Psychology, 26(4), 331-346.

Muraven, M., Shmueli, D., \& Burkley, E. (2006). Conserving self-control strength. Journal of Personality and Social Psychology, 91(3), 524-537.

Neider, L. L., \& Schriesheim, C. A. (2011). The Authentic Leadership Inventory (ALI): Development and empirical tests. Leadership Quarterly, 22(6), 1146-1164.

Oppenheimer, D. M., Meyvis, T., \& Davidenko, N. (2009). Instructional manipulation checks: Detecting satisficing to increase statistical power. Journal of Experimental Social Psychology, 45(4), 867-872.

Podsakoff, P. M., MacKenzie, S. B., Lee, J. Y., \& Podsakoff, N. P. (2003). Common method 
biases in behavioral research: A critical review of the literature and recommended remedies. Journal of Applied Psychology, 88(5), 879-903.

Rahimnia, F., \& Sharifirad, M. S. (2015). Authentic leadership and employee well-Being: The mediating role of attachment insecurity. Journal of Business Ethics, 132(2), 363377.

Salancik, G. R., \& Pfeffer, J. (1978). A social information processing approach to job attitudes and task design. Administrative Science Quarterly, 23(2), 224-253.

Schaubroeck, J., \& Jones, J. R. (2000). Antecedents of workplace emotional labor dimensions and moderators of their effects on physical symptoms. Journal of Organizational Behavior, 21(2), 163-183.

Schimmack, U., Radhakrishnan, P., Oishi, S., Dzokoto, V., \& Ahadi, S. (2002). Culture, personality, and subjective well-being: Integrating process models of life satisfaction. Journal of Personality and Social Psychology, 82(4), 582-593.

Schreiber, J. B., Stage, F. K., King, J., Nora, A., \& Barlow, E. A. (2006). Reporting structural equation modeling and confirmatory factor analysis results: A review. Journal of Educational Research, 99(6), 323-338.

Schwartz Rounds. (n.d.). Retrieved July 3, 2020, from https://www.pointofcarefoundation.org.uk/our-work/schwartz-rounds/

Skakon, J., Nielsen, K., Borg, V., \& Guzman, J. (2010). Are leaders' well-being, behaviours and style associated with the affective well-being of their employees? A systematic review of three decades of research. Work and Stress, 24(2), 107-139.

Song, Y., Lu, H., Hu, S., Xu, M., Li, X., \& Liu, J. (2015). Regulating emotion to improve physical health through the amygdala. Social Cognitive and Affective Neuroscience, 
$10(4), 523-530$.

Thompson, E. R. (2007). Development and validation of an internationally reliable shortform of the Positive and Negative Affect Schedule (PANAS). Journal of Cross-Cultural Psychology, 38(2), 227-242.

Uhl-Bien, M. (2006). Relational Leadership Theory: Exploring the social processes of leadership and organizing. Leadership Quarterly, 17(6), 654-676. https://doi.org/10.1016/j.leaqua.2006.10.007

Walumbwa, F. O., Avolio, B. J., Gardner, W. L., Wernsing, T. S., \& Peterson, S. J. (2008). Authentic leadership: Development and validation of a theory-based measure. Journal of Management, 34(1), 89-126.

Wang, H., Sui, Y., Luthans, F., Wang, D., \& Wu, Y. (2014). Impact of authentic leadership on performance: Role of followers' positive psychological capital and relational processes. Journal of Organizational Behavior, 35(1), 5-21.

Ware, J. E. J., Kosinski, M., \& Keller, S. D. (1996). A 12-Item Short-Form Health Survey: Construction of scales and preliminary tests of reliability and validity. Medical Care, $34(3), 220-233$.

Zalesny, M. D., \& Ford, J. K. (1990). Extending the social information processing perspective: New links to attitudes, behaviors, and perceptions. Organizational Behavior and Human Decision Processes, 47, 205-246.

Zhou, L., Liu, Y., Chen, Z., \& Zhao, S. (2018). Psychological mechanisms linking ethical climate to employee whistle-blowing intention. Journal of Managerial Psychology, 33(2), 196-213. 
Table I.

Means,

standard

deviations, and

bivariate

correlations for

Study $1 \&$

Variable

Study 1

Study 2

12

3

4

5

6

$\begin{array}{lll}7 & 8 & 9\end{array}$

1. Company

$\begin{array}{ll}M & \\ 1.28 & .45\end{array}$

2. Gender ${ }^{b}$

$1.72 \quad .45$

$\begin{array}{cc}M & S D \\ -- & --\end{array}$

3. Age

1.38

$\begin{array}{lll}42.85 & 9.46 & 30.34\end{array}$

.48

$\begin{array}{cc}-- & -- \\ .41 * * & -- \\ .26 * * & .12\end{array}$

$--$

$--$

$--$

03

$--$

.12

$--$

$--$

4. Positive affect

$\begin{array}{llllll}3.35 & .73 & 3.35 & .75 & .14 & .07\end{array}$

$-.07$

.03

$-.17 * \quad .04$

$-.08$

$.12-.01$

5. Negative affect

$1.73 \quad .66$

.14
-.09

.01

$--$

$-.46 * *$

$34 * *$

$.35 * *$

$61 * *-3 * *$

6. AL

3.75

.75

1.79
3.44

.9

$.32 * * \quad .04$

.07

7. Perceived climate

3.77

of authenticity

8. Health

$49.85 \quad 5.91$

3.86

$\begin{array}{ll}9 & .32 * * \\ 56 & .27 * *\end{array}$

$-.08$

$-.12$

$-.21 *$

$-.12$

$-.49 *$

$.36 * *$

9. Neuroticism

(Study 2)

Notes. Values below the diagonal are for Study $1(n=104)$; values above the diagonal are for Study $2(n=146) .{ }^{*} p<0.05 ;{ }^{* *} p<$

Study 2

$0.01 .{ }^{a} 1$ = pharmaceutical company; 2 = geriatric care company. ${ }^{\mathrm{b}} 1=$ male; $2=$ female 


\begin{tabular}{lcccccc}
\hline Variables & \multicolumn{2}{c}{ Perceived climate of authenticity } & \multicolumn{3}{c}{ Health } \\
\hline & $B$ & $S E$ & $p$ & $B$ & $S E$ & $p$ \\
\hline 1. Company & .29 & .12 & .02 & -4.28 & 1.15 & .00 \\
2. Genderb & $-.23(.12)$ & $.11(.08)$ & $.04(.15)$ & $-1.6(-1.49)$ & $1.07(.72)$ & $.14(.04)$ \\
3. Age & $-.01(-.01)$ & $.01(.01)$ & $.32(.19)$ & $.02(.04)$ & $.04(.04)$ & $.64(.29)$ \\
4. Positive affect & $.05(.21)$ & $.07(.06)$ & $.43(.00)$ & $2.91(3.17)$ & $.66(.56)$ & $.00(.00)$ \\
5. Negative affect & $-.02(.04)$ & $.07(.06)$ & $.83(.59)$ & $-2.8(-1.69)$ & $.68(.56)$ & $.00(.00)$ \\
6. AL & $.25(.16)$ & $.07(.05)$ & $.00(.00)$ & $.74(.43)$ & $.65(.42)$ & $.25(.31)$ \\
7. Perceived climate of authenticity & & & & $2.56(9.12)$ & $.92(2.74)$ & $.00(.00)$ \\
8. Neuroticism (Study 2) & & & & $(-9.08)$ & $(2.9)$ & $(.00)$ \\
9. Perceived climate of authenticity & & & & $(2.17)$ & $(.76)$ & $(.00)$ \\
X neuroticism (Study 2) & & & & & & \\
\hline
\end{tabular}

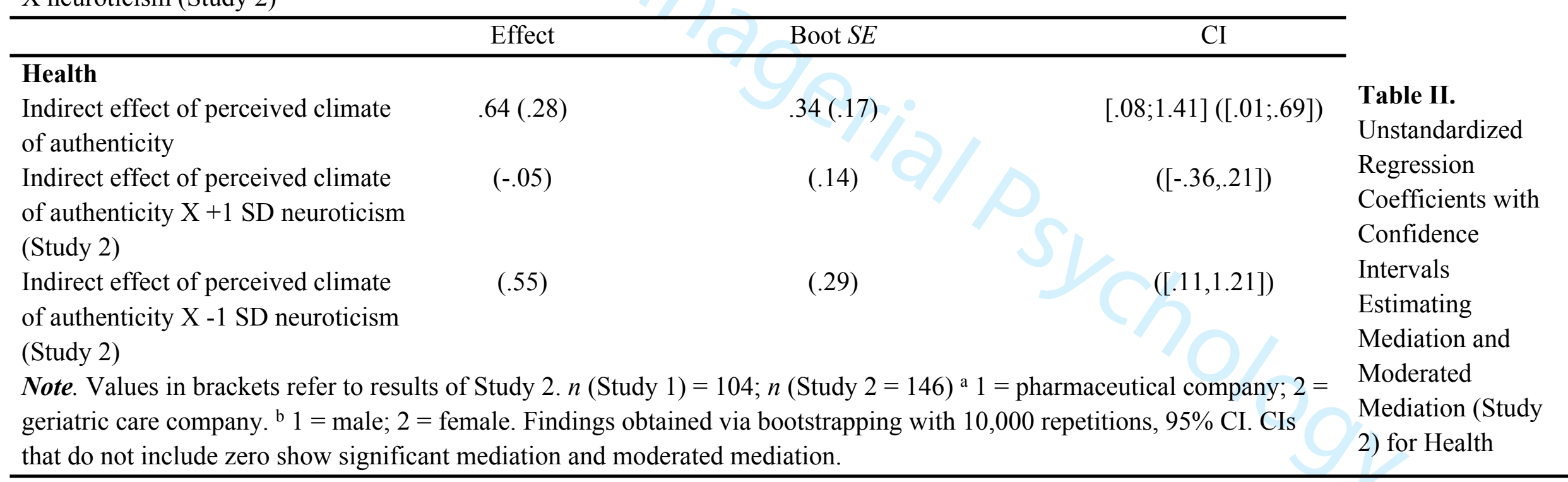

